\title{
Pengaruh Pendidikan Kesehatan dengan Media Leaflet terhadap Pengetahuan Remaja Putri dalam Deteksi Dini Kanker Payudara Melalui Pemeriksaan Payudara Sendiri (Sadari) Di SMA.N 8 Kota Jambi
}

\author{
Nel Efni, Tina Yuli Fatmawati* \\ STIKes Baliturrahim, Jln Prof M Yamin SH, No 30, Kelurahan Lebak Bandung \\ ${ }^{*}$ Correspondence email: tinayulifatmawati@gmail.com
}

\begin{abstract}
Abstrak. Prevalensi tumor/ kanker di Indonesia tahun 2017adalah 1.4 per 1000 penduduk, atau sekitar 347.000 orang. Kanker tertinggi di Indonesia pada perempuan adalah kanker payudara dan kanker leher rahim. Kanker payudara menempati posisi kedua sebagai penyakit kanker terbanyak yang menyerang perempuan di Indonesia setelah kanker leher rahim. Satu-satunya cara yang paling efektif yang dapat dilakukan untuk deteksi dini kemungkinan timbulnya penyakit ini adalah dengan melakukan Pemeriksaan Payudara Sendiri (SADARI). Penelitian ini bertujuan untuk mengetahui pengaruh pendidikan kesehatan dengan media leafleat terhadap pengetahuan remaja putri dalam melakukan deteksi dini kanker payudara melalui pemeriksaan payudara sendiri di SMA.N 8 Kota Jambi. Populasi dalam penelitian ini adalah Remaja Putri di SMU N 8 Kota Jambi dengan jumlah sampel 30 orang. Pengambilan sampel dengan cara Purposive Sampling. Data dianalisis menggunakan analisa univariat dan bivariat dengan Uji Paired Sample T Test. Hasil penelitian disimpulkan bahwa secara statistik ada pengaruh pendidikan kesehatan dengan media leaflet terhadap pengetahuan remaja putri dalam melakukan deteksi dini kanker payudara melalui pemeriksaan payudara sendiri di SMA.N 8 Kota Jambi $(p$ value <0.005)
\end{abstract}

Kata Kunci: Deteksi Dini; Kanker Payudara; Pemeriksaan payudara; Remaja putri

\begin{abstract}
The prevalence of tumors / cancer in Indonesia in 2017 is 1.4 per 1000 population, or around 347,000 people. The highest cancer in Indonesia in women is breast cancer and cervical cancer. Breast cancer is in the second position as the most common cancer affecting women in Indonesia after cervical cancer. The only most effective way that can be done for early detection of the possibility of this disease is to perform Breast Self-Examination (BSE). This study aims to determine the effect of health education with leafleat media on the knowledge of young women in early detection of breast cancer through breast selfexamination at SMA $N 8$ Jambi City. The population in this study were young women at SMU $N 8$ Jambi City.The sampling using purposive sampling with 30 respondent. Data were analyzed using univariate and bivariate analysis with Paired Sample T Test. The results of the study concluded there was an effect of health education with leaflet media on the knowledge of young women in early detection of breast cancer through breast self-examination at SMA N 8 Jambi City ( $p$ value <0.005).
\end{abstract}

Keyword: Early detection; Breast cancer; Breast examination; Teenage girl

\section{PENDAHULUAN}

Penyakit kanker merupakan salah satu penyebab utama kematian dan jenis kanker yang lebih banyak terjadi pada wanita adalah kanker payudara. Salah satu upaya untuk pencegahan kanker payudara adalah melalui deteksi dini yang dikenal dengan metode SADARI (pemeriksaan payudara sendiri). Berdasarkan data Riset Kesehatan Dasar (2017) prevalensi tumor/ kanker di Indonesia adalah 1.4 per 1000 penduduk, atau sekitar 347.000 orang. Kanker tertinggi di Indonesia pada perempuan adalah kanker payudara dan kanker leher rahim. Berdasarkan estimasi GLOBOCAN (IARC) tahun 2012, insidens kanker payudara masih menempati urutan pertama kasus baru dan kematian akibat kanker, yaitu sebesar 43,3\% dan 12,9\% pada penduduk perempuan di dunia (Kementrian Kesehatan RI Pusat Data dan Informasi Kesehatan, 2015).

Menurut Kementerian Kesehatan Republik Indonesia (2015) jumlah penderita kanker di Indonesia telah mencapai angka sebesar 61.682 penderita dengan prevalensi 12/100.000 perempuan. Selain itu, kanker payudara juga menempati posisi kedua sebagai penyakit kanker terbanyak yang menyerang perempuan di Indonesia setelah kanker leher rahim. Provinsi Jawa Timur sendiri juga merupakan provinsi kedua dengan estimasi penderita kanker payudara terbanyak di Indonesia setelah Jawa Tengah dengan prevalensi 0,5.

Soemitro (2012) menjelaskan SADARI adalah bagian yang tidak terpisahkan dari pemeriksaan payudara setiap wanita. Pemeriksaan payudara sendiri dilakukan setiap 1 bulan sekali dan dapat menjadi instrumen penapisan yang efektif untuk mengetahui lesi payudara. Satu-satunya cara yang paling efektif yang dapat dilakukan untuk deteksi dini kemungkinan timbulnya penyakit ini adalah dengan melakukan SADARI yang dapat menekan angka kematian sebesar 25-30\%. Untuk para wanita yang memiliki tingkat pengetahuan dan pemahaman yang rendah tentang kanker payudara dan cara deteksinya perlu diberikan 
informasi mengenai kanker payudara dan cara deteksinya yaitu SADARI sejak usia remaja

Pendidikan kesehatan adalah serangkaian upaya yang dilakukan untuk mempengaruhi orang lain, individu, kelompok, keluarga, maupun masyarakat sehingga terlaksana suatu perilaku hidup bersih dan sehat (Efendi \& Makhfudli, 2013). Diharapkan dengan pendidikan kesehatan yang telah diikuti benar-benar dapat mengubah perilaku sehari-harinya.

Penelitian terdahulu tentang pengaruh pelaksanaan pemeriksaan payudara sendiri (sadari) terhadap pengetahuan dan kemampuan siswi dalam upaya deteksi dini kanker payudara di Smp Neg. 1 Sibulue Kab. Bone, bahwa sebelum pendidikan kesehatan 92\% siswi memiliki tingkat pengetahuan yang cukup dan setelah pendidikan kesehatan $93.2 \%$ pengetahuan siswi dalam kategori baik, sedangkan sebelum pendidikan kesehatan $100 \%$ siswi tidak mampu melakukan SADARI dan setelah pendidikan kesehatan $87.5 \%$ mampu untuk melakukan SADARI. Dari hasil uji statistik pengetahuan dan kemampuan sebelum dan setelah pendidikan kesehatan (Damayanti, 2017).

SMA.N 8 Kota Jambi merupakan salah satu Sekolah Menengah Atas yang berada di Kecamatan Kota Baru dengan Jumlah siswi kelas XI sebanyak 240.Berdasarkan survei awal yang dilakukan pada bulan Agustus 2019 kepada 4 orang remaja putri tentang pengetahuan dalam melaksanakan deteksi dini kanker payudara melalui SADARI, keempat remaja tersebut tidak mengetahui kapan dilakukan pemeriksaan sadari dan bagaimana cara mendeteksi dini kanker payudara melalui SADARI sehingga tidak pernah melakukan SADARI.

\section{METODE}

Desain penelitian ini merupakan penelitian preeksperimen yang menggunakan One Group Pre Test dan Post Test yaitu pengukuran pengetahuan sebelum dan sesudah pendidikan kesehatan. Sampel penelitian ini ialah remaja putri di SMU N 8 berjumlah 30 orang. Pengambilan sampel penelitian dengan cara simple random sampling. Instrument yang digunakan adalah kuesioner. Teknik analisis data yang digunakan dalam adalah Uji Paired Sample $T$ Test dengan tingkat kepercayaan $95 \%$.

\section{HASIL DAN PEMBAHASAN Analisi univariat}

Tabel 1. Distribusi Frekuensi Responden Berdasarkan Umur

\begin{tabular}{lll}
\hline Umur & Jumlah & Prentase \\
\hline 18 Tahun & 7 & 23.3 \\
17 Tahun & 11 & 36.7 \\
16 Tahun & 10 & 33.3 \\
15 Tahun & 2 & 6.7 \\
Jumlah & $\mathbf{3 0}$ & $\mathbf{1 0 0}$ \\
\hline
\end{tabular}

Berdasarkan tabel diatas diketahui dari 30 responden, mayoritas responden berumur 17 tahun 11 orang ( $36.7 \%)$

\section{Gambaran pengetahun responden sebelum diberi pendidikan kesehatan (Pre Test) dan sesudah diberikan pendidikan kesehatan (Post Test).}

Tabel. 2 Distribusi Gambaran pengetahun responden sebelum diberi pendidikan kesehatan (Pre Test) dan sesudah diberikan pendidikan kesehatan (Post Test) tentang SADARI.

\begin{tabular}{|c|c|c|}
\hline Responden & $\begin{array}{c}\text { Sebelum Diberikan } \\
\text { pendidikan } \\
\text { kesehatan tentang } \\
\text { SADARI }\end{array}$ & $\begin{array}{c}\text { Sesudah Diberikan } \\
\text { pendidikan } \\
\text { kesehatan tentang } \\
\text { SADARI }\end{array}$ \\
\hline 1 & 5 & 8 \\
\hline 2 & 8 & 9 \\
\hline 3 & 6 & 9 \\
\hline 4 & 6 & 8 \\
\hline 5 & 6 & 9 \\
\hline 6 & 8 & 9 \\
\hline 7 & 5 & 8 \\
\hline 8 & 8 & 9 \\
\hline 9 & 5 & 8 \\
\hline 10 & 8 & 8 \\
\hline 11 & 7 & 8 \\
\hline 12 & 8 & 9 \\
\hline 13 & 9 & 10 \\
\hline 14 & 7 & 10 \\
\hline 15 & 7 & 8 \\
\hline 16 & 8 & 8 \\
\hline 17 & 4 & 7 \\
\hline 18 & 5 & 10 \\
\hline 19 & 8 & 10 \\
\hline 20 & 4 & 6 \\
\hline 21 & 7 & 9 \\
\hline 22 & 6 & 6 \\
\hline 23 & 4 & 8 \\
\hline 24 & 6 & 9 \\
\hline 25 & 4 & 6 \\
\hline 26 & 6 & 9 \\
\hline 27 & 7 & 9 \\
\hline 28 & 9 & 9 \\
\hline 29 & 5 & 8 \\
\hline 30 & 4 & 8 \\
\hline Jumlah & 190 & 252 \\
\hline Rata-rata & 6,33 & 8.33 \\
\hline
\end{tabular}

Berdasarkan tabel.2 diketahui hasil gambaran responden sebelum diberi pendidikan kesehatan dengan jumlah 190 dan nilai rata-rata 6,33 dan gambaran responden setelah diberi pendidikan kesehatan dengan jumlah 252 dan nilai rata-rata 8,33.

Hasil penelitian menujukkan bahwa saat pre test kemampuan melakukan SADARI dalam kategori mampu (>60\%) sebanyak 19 responden dan kemudian meningkat menjadi $100 \%$ setelah diberikan intervensi kesehatan pada saat post test, sedangkan dalam kategori tidak mampu sebanyak 11 responden dan kemudian 
menurun menjadi $0 \%$ setelah diberikan intervensi pada saat post test.

Dari penelitian diatas masih banyak responden yang belum memahami dan tahu bagaimana cara melakukan pemeriksaan payudara sendiri, sehingga perlunya pendidikan kesehatan pada siswi agar pemahaman tentang tehnik SADARI dapat meningkat.

\section{Analisis Bivariat}

Tabel 3. Pengaruh pendidikan kesehatan dengan media leafleat terhadap pengetahuan remaja putri dalam melakukan deteksi dini kanker payudara melalui pemeriksaan payudara sendiri di SMA.N 8 Kota Jambi

\begin{tabular}{lrllll}
\hline Variabel & & Mean & $\begin{array}{l}\text { Standar } \\
\text { Deviasi }\end{array}$ & $\begin{array}{l}\text { Std. } \\
\text { Eror }\end{array}$ & $\begin{array}{l}\boldsymbol{P} \\
\text { Value }\end{array}$ \\
\hline $\begin{array}{l}\text { gambaran } \\
\text { sebelum }\end{array}$ & $\begin{array}{r}\text { responden } \\
\text { diberi }\end{array}$ & 6,33 & .971 & .297 & 0.000 \\
pendidikan kesehatan & & & & \\
gambaran & $\begin{array}{r}\text { responden } \\
\text { diberi } \\
\text { setelah }\end{array}$ & 8.33 & 1.632 & .177 & \\
pendidikan kesehatan & & & & \\
\hline
\end{tabular}

Hasil analisis diketahui bahwa gambaran responden sebelum diberi pendidikan kesehatan, dimana rata-rata adalah 6,33 dengan standar deviasi 0,971 dan standar eror 0,297 sedangkan gambaran responden setelah diberi pendidikan kesehatan dengan rata-rata 8.33 dengan standar deviasi 0,177 dan standar eror 0,177 . Hasil uji statistik paired $t$-test didapatkan nilai $p$ value $=0,000<0,05$ dengan selisih nilai mean 2,00. Maka dapat disimpulkan bahwa secara statistik ada Pengaruh pendidikan kesehatan dengan media leafleat terhadap pengetahuan remaja putri dalam melakukan deteksi dini kanker payudara melalui pemeriksaan payudara sendiri di SMA.N 8 Kota Jambi.

Penelitian ini sama dengan penelitian Saragih (2020), Dari hasil uji statistik dijelaskan pengetahuan dan kemampuan sebelum dan setelah pendidikan kesehatan diperoleh nilai $\mathrm{p}=0.000 \quad(\mathrm{p}<0.05)$. Dapat disimpulkan bahwa ada pengaruh pendidikan kesehatan tentang pemeriksaan payudara sendiri (SADARI) terhadap pengetahuan siswi dalam upaya deteksi dini kanker payudara di SMK Kesehatan Imelda Medan.

Penelitian lain yang sejalan dengan penelitian ini adalah penelitian Putri, 2018, berdasarkan hasil analisis diketahui bahwa pemberian pendidikan kesehatan menggunakan video, secara statistik dengan uji Wilcoxon didapatkan nilai $\mathrm{p}=0,000(\mathrm{p}<0,05)$ sehingga dapat disimpulkan terdapat peningkatan pengetahuan yang bermakna antara sebelum dan sesudah diberikan video. Kanker payudara merupakan penyakit yang tidak mengenal golongan usia, remaja 15 tahun pun dapat saja terkena kanker payudara, untuk itu deteksi dini kanker payudara sangat dianjurkan dilakukan sejak wanita usia remaja. SADARI adalah suatu prosedur untuk mengetahui kelainan-kelainan pada payudara dengan melakukan inspeksi secara berkala, misalnya sebelum melakukan pemeriksaan payudara terlebih dahulu harus mencuci tangan agar tidak terjadi infeksi pada payudara, serta penggantian bra merupakan salah satu dari penanggulangan untuk pencegahan infeksi pada payudara. Tujuan dilakukannya SADARI adalah untuk mendeteksi adanya kelainan-kelainan pada payudara baik struktur, bentuk ataupun tekstur (Soemitro, 2012).

Manfaat SADARI adalah untuk mendeteksi sedini mungkin adanya kelainan pada payudara karena kanker payudara pada hakikatnya dapat diketahui secara dini oleh para remaja wanita. Setiap wanita mempunyai bentuk dan ukuran payudara yang berbeda, bila wanita memeriksa payudara sendiri secara teratur, setiap bulan setelah haid, wanita dapat merasakan bagaimana payudara wanita yang normal. Bila ada perubahan tentu wanita dapat mengetahuinya dengan mudah (Sari, 2012).

Menurut Pratiwi (2011) menjelaskan bahwa setiap wanita akan terhindar dari kanker payudara, jika saja mereka dapat melakukan pemeriksaan SADARI sedini mungkin, setidaknya dimulai remaja (remaja berumur lebih dari 12 tahun dan kurang dari 24 tahun).

Salah satu untuk meningkatkan pengetahuan adalah melalui pendidikan kesehatan. Pendidikan kesehatan bertujuan untuk mengubah pengetahuan, sikap, dan keterampilan individu atau kelompok masyarakat dalam bidang kesehatan, membina dan memelihara perilaku hidup sehat 20 serta berperan aktif dalam upaya mewujudkan derajat kesehatan secara optimal.

Satu-satunya cara yang paling efektif yang dapat dilakukan untuk deteksi dini kemungkinan timbulnya penyakit ini adalah dengan melakukan Pemeriksaan Payudara Sendiri (SADARI) yang dapat menekan angka kematian sebesar 25-30\%. Peran media menjadi penting dalam membentuk pengetahuan seseorang dalam memahami masalah kesehatan reproduksi. Informasi yang kurang tepat, akan sangat mempengaruhi pengetahuan yang menjadi kurang tepat juga. Majunya teknologi akan tersedia bermacam-macam media yang dapat mempengaruhi pengetahuan masyarakat tentang inovasi baru. Contoh media yang didesain secara khusus untuk mencapai masyarakat luas seperti media audiovisual (televisi), media audio (radio), media cetak (koran, majalah), dan internet, (Notoadmodjo, 2011).

Untuk itu para remaja yang memiliki tingkat pengetahuan dan pemahaman yang kurang tentang deteksi dini kanker payudara hendaknya selalu mencari informasi dari berbagai media baik media cetak maupun elektronik atau dengan mengikuti kegiatan penyuluhan yang dilakukan di sekolah maupun dimasyarakat.

\section{SIMPULAN}

Hasil penelitian ini dapat disimpulkan pendidikan kesehatan dengan media leaflet dapat meningkatkan pengetahuan remaja putri dalam melakukan deteksi dini 
kanker payudara melalui pemeriksaan payudara sendiri di SMA.N 8 Kota Jambi.

\section{DAFTAR PUSTAKA}

Damayanti, Riska, 2017. Pengaruh Pelaksanaan pemeriksaan Payudara Sendiri (Sadari) Terhadap Pengetahuan Dan Kemampuan siswi Dalam Upaya Deteksi Dini Kanker Payudaradi SMP Neg.1 Sibulue Kab. Bone. Skripsi FK Unhas

Efendi, F., \& Makhfudli. (2013). Keperawatan Kesehatan Komunitas Teori dan Praktik dalam Keperawatan. Jakarta: Salemba Medika

Kementrian Kesehatan RI Pusat Data dan Informasi Kesehatan. (2015) Infodatin, diakses Agustus, 2019

Kementrian Kesehatan RI 2017 . Riset Kesehatan Dasar.

Notoadmodjo, S. 2011. Ilmu Kesehatan Masyarakat. Rineka Cipta : Jakarta

Pratiwi. 2011. Buku Pintar Kesehatan Wanita. Imperium. Jogjakarta

Putri ,I.L. 2018. Skripsi Kesehatan Dengan Video Terhadap Pengetahuan Tentang pemeriksaan Payudara Sendiri(Sadari) Pada wanita Usia Subur (Wus). Politeknik Kesehatan Kementerian Kesehatan

Sari, dkk. 2012. Kesehatan Wanita. Swadaya Salemba. Jakarta

Saragih G, 2020. Pengaruh Pendidikan Kesehatan "Sadari" Terhadap Pengetahuandeteksi Dini Kanker Payudara Pada Remaja Putri Di Smk Kesehatan Imelda Medan. Journal Article Jurnal $\underline{\text { Imiah Kebidanan Imelda }}$

Soemitro, M. 2012. Blak-Blakan Kanker. Jogyakarta: Graha Qinita 